\title{
Effects of Norepinephrine Infusion on Myocardial High-Energy Phosphate Content and Turnover in the Living Rat
}

\author{
John A. Bittl, James A. Balschi, and Joanne S. Ingwall \\ Department of Medicine, Brigham and Women's Hospital, Harvard Medical School, and the Harvard Medical School \\ Nuclear Magnetic Resonance Laboratory, Boston, Massachusetts 02115
}

\begin{abstract}
Using ${ }^{31}$ P-nuclear magnetic resonance, we studied the relationship between myocardial high-energy phosphate content and flux values for the creatine kinase reaction in the living rat under inotropic states achieved during norepinephrine infusion and halothane anesthesia. Under $2 \%$ halothane anesthesia $(n=4)$, $1 \%$ halothane anesthesia $(n=5)$ and norepinephrine infusion ( $n$ $=4$ ), rats developed rate-pressure products of 19.5 \pm 1.6 , 32.0 \pm 3.5 , and $48.5 \pm 2.0 \times 1,000 \mathrm{mmHg} / \mathrm{min}$, respectively. Adenosine triphosphate content was not affected by inotropic state, ranging from $24.3 \pm 1.1$ to $25.6 \pm 1.1 \mu \mathrm{mol} / \mathrm{g}$ dry weight, but creatine phosphate content varied inversely and reversibly with cardiac performance from $45.6 \pm 6.0$ under $2 \%$ halothane to $26.0 \pm 6.5 \mu \mathrm{mol} / \mathrm{g}$ dry weight during norepinephrine infusion. The flux values for the creatine kinase reaction were $15.4 \pm 4.6$, $20.5 \pm 2.0$, and $30.1 \pm 7.9 \mu \mathrm{mol} / \mathrm{g}$ dry weight per s under $2 \%$ halothane, $1 \%$ halothane, and $1 \%$ halothane with norepinephrine, respectively. These results suggest that the turnover of myocardial high-energy phosphate compounds, not their tissue contents, matches cardiac performance during inotropic stimulation.
\end{abstract}

\section{Introduction}

Oxidative metabolism generates most of the ATP for cardiac contraction. Consequently, myocardial oxygen consumption correlates closely with cardiac energy utilization. The major determinants of myocardial oxygen consumption are governed chiefly by systolic performance of the left ventricle: wall stress, inotropic state and heart rate (1-4). In the living animal, increases in wall stress and inotropic state stimulate oxygen consumption to a much greater degree than increasing heart rate $(5,6)$.

In heart, energy production matches energy utilization so that tissue ATP content remains constant, or nearly so, despite large changes in ATP turnover and cardiac performance. In contrast, increases in wall stress and inotropic stimulation decrease the myocardial content of creatine phosphate in both the intact animal (7) and in isolated hearts $(4,8,9)$. Consistent with its weaker effect on oxygen consumption, increasing the heart rate by atrial pacing in the intact animal has no effect on myocardial ATP or creatine phosphate (10).

During inotropic stimulation, the creatine kinase reaction

Presented at the Annual Meeting of the American Federation of Clinical Research, Washington, DC, 5 May 1986.

Address reprint requests to Dr. Bittl.

Received for publication 4 September 1986 and in revised form 26 December 1986.

J. Clin. Invest.

(c) The American Society for Clinical Investigation, Inc.

0021-9738/87/06/1852/08 \$1.00

Volume 79, June 1987, 1852-1859
(EC 2.7.3.2) may be important for the close coupling between ATP synthesis and utilization in the myocardium. The intracellular localization of creatine kinase isozymes, with the mitochondrial form bound to mitochondria (11-13) and the MM form attached to the $M$-line of the sarcomere $(14,15)$, insures that ADP be available for oxidative phosphorylation and that ATP be replenished at the contractile apparatus. At constant $\mathrm{pH}$, the reaction is second-order in creatine phosphate and ADP: $\mathrm{Mg} \cdot \mathrm{ADP}+\mathrm{CrP} \rightleftharpoons \mathrm{Mg} \cdot \mathrm{ATP}+$ creatine.

The ${ }^{31} \mathrm{P}-\mathrm{NMR}$ technique of magnetization transfer has been used to define the rate of ATP synthesis in isolated hearts from oxidative phosphorylation $(14,16)$ and from creatine phosphate via the creatine kinase reaction $(14,9,16-18)$. The rates of ATP turnover, traditionally estimated by oxygen consumption, can now be measured with magnetization transfer methods. However, studies that compared flux through the creatine kinase reaction to the level of cardiac performance and mitochondrial respiration have produced conflicting results. Some studies have found no relationship between flux and cardiac performance $(16,17)$, suggesting that creatine kinase is in thermodynamic equilibrium in the buffer-perfused heart. On the other hand, other studies have demonstrated that flux through the creatine kinase reaction increases with cardiac performance and oxygen consumption, supporting the evidence that creatine kinase plays an important role in coupling myocardial energy production to utilization $(4,9,18)$.

Using ${ }^{31} \mathrm{P}$-nuclear magnetic resonance (NMR) ${ }^{1}$ spectroscopy, we measured high-energy phosphate content in hearts of animals during norepinephrine infusion and observed a reversible depression of creatine phosphate but no change in ATP. In addition, we have studied creatine kinase kinetics in the hearts of these animals in order to define the effect of cardiac performance on ATP turnover. Norepinephrine infusion and various doses of halothane anesthesia produced a broad range of cardiac performance that could not be achieved with ventricular pacing. The simultaneous hemodynamic and metabolic measurements showed that inotropic stimulation reversibly alters creatine phosphate but not ATP content and increases flux through the reaction catalyzed by creatine kinase.

\section{Methods}

Animals. Male Sprague-Dawley rats, weighing 300-400 g, were fed ad lib. Each animal was anesthetized initially with $2 \%$ halothane vaporized (Fluotec Vaporizer, Cyprane Limited) and delivered by constant flow (small animal respirator, Harvard Apparatus Co., Natick, MA) through a nasal cone. We intubated the animal via tracheostomy with a $1.5-\mathrm{cm}$ length of polyethylene tubing (Clay-Adams, Parsippany, NJ: $1.14 \mathrm{~mm}$ ID, $1.57 \mathrm{~mm}$ OD) connected to Tygon tubing ( $3.2 \mathrm{~mm} \mathrm{ID,} 6.4 \mathrm{~mm}$ OD)

1. Abbreviations used in this paper: NMR, nuclear magnetic resonance; $\mathrm{T} 1$, longitudinal relaxation time. 
attached to the respirator, which was adjusted to deliver room air at a tidal volume of $10 \mathrm{ml} / \mathrm{kg} 70$ times per min.

Hemodynamic measurements. We cannulated the left common carotid artery and the right internal jugular vein with $2.0 \mathrm{~cm}$ lengths of polyethylene tubing $(0.73 \mathrm{~mm}$ ID, $0.98 \mathrm{~mm} \mathrm{OD)} \mathrm{connected} \mathrm{to} 120 \mathrm{~cm}$ of Tygon Microbore Tubing (Norton Plastics, Akron, OH: $1.27 \mathrm{~mm}$ ID, $2.34 \mathrm{~mm}$ OD). The carotid cannula was advanced to the aorta and connected to a Statham P23Db pressure transducer (Gould Instruments, Santa Clara, CA) for continuous measurement of central aortic pressure and heart rate on a 7754B recorder and $8805 \mathrm{D}$ pressure amplifier (Hewlett-Packard Co., Palo Alto, CA). The transducer system exhibited excellent frequency and damping characteristics $(n=4$, mean \pm SD): damped natural frequency $N_{\mathrm{d}}=51 \pm 7 \mathrm{~Hz}$; damping coefficient $D=0.50 \pm 0.12$; and undamped natural frequency $N=67 \pm 8 \mathrm{~Hz}$ (19). The internal jugular line was connected to a stopcock and syringes that contained $145 \mathrm{mM}$ $\mathrm{NaCl}$ with either heparin (bovine, Abbot Laboratories, North Chicago, IL) $10 \mathrm{U} / \mathrm{ml}$ or norepinephrine (Breon Laboratories, New York) in concentration of $10 \mu \mathrm{g} / \mathrm{ml}$ in $145 \mathrm{mM} \mathrm{NaCl}$. After baseline hemodynamic measurements were recorded, we made a subxiphoid incision, penetrated the anterior diaphragm and made a midline sternotomy, avoiding the internal thoracic arteries which were ligated superior to the thymus. A transverse sternal and thoracic incision was made just inferior to the ligated internal thoracic arteries and extended laterally to the mid-axillary line and inferiorly to the costal margin. Estimated blood loss for each of the preparations for this study was $<2.0 \mathrm{ml}$ and was replaced with equal volume of $145 \mathrm{mM} \mathrm{NaCl}$. The preparation is illustrated in Fig. 1 .

The body temperature of the rat was maintained by running water at $35^{\circ} \mathrm{C}$ through two loops of Tygon tubing placed against the body of the animal. Hemodynamic stability of the preparation persisted for $>4$ $h$ in control experiments. All measurements reported here were made in preparations within $4 \mathrm{~h}$ after the onset of anesthesia.

At the end of the study, halothane was increased to $4 \%$ to produce lethal cardiovascular collapse.

NMR measurements. The animal was placed in an aluminum probe with the apex of the left ventricle loosely positioned against a parafilmcovered, $1.4 \mathrm{~cm}$, two-turn surface coil. Intercostal muscle was retracted $>1 \mathrm{~cm}$ from the coil. Ventilation and vascular lines ran through the length of the probe. The probe was placed in the bore of an $360 \mathrm{MHz}$

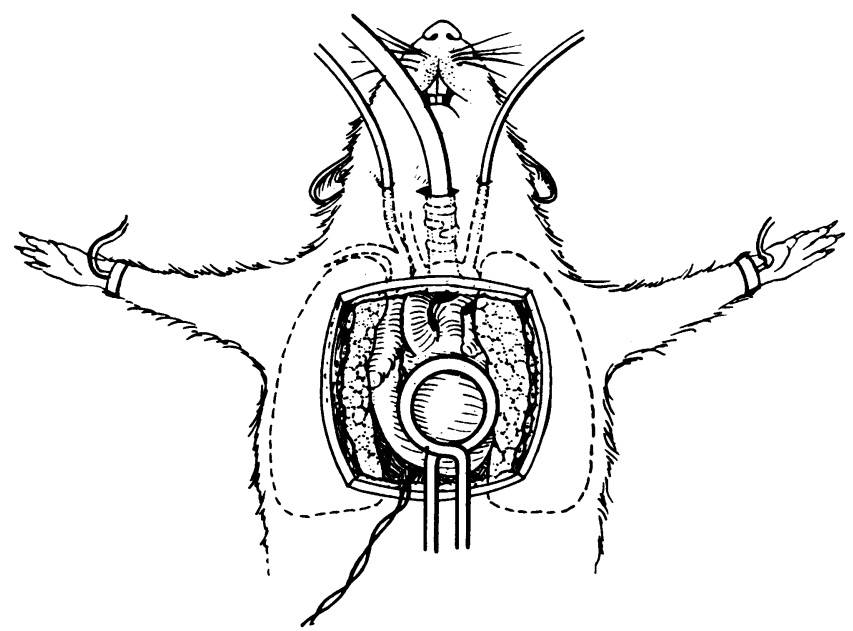

Figure 1. The open-chest rat preparation. Polyethylene cannulas were placed in the left common carotid artery for blood pressure measurement, the right internal jugular vein for administration of fluids, and the trachea for ventilation and anesthesia. Pin electrodes were placed on the limbs for recording electrocardiograms. Bipolar pacing electrodes were attached to the posterior wall of the left ventricle for pacing studies. The instrumented animal was positioned in a surface coil probe so that a two-turn surface coil lay directly over the left ventricular apex. magnet (Oxford Instruments, Bedford, MA) interfaced with a NT360 (Nicolet Instrument Corp., Madison, WI) spectrometer. The magnetic field was shimmed by maximizing the signal intensity for ${ }^{23} \mathrm{Na}$ at 95.24 MHz. ${ }^{31} \mathrm{P}-\mathrm{NMR}$ spectra were recorded by signal-averaging 32 scans obtained after a $15-\mu \mathrm{s}$ broadband pulse and a 12.5-s interpulse delay.

Studies with phantoms showed that the surface coil obtained 50\% of the signal from the superficial volume $2 \mathrm{~mm}$ deep and that $75 \%$ of the signal arose from a volume $4 \mathrm{~mm}$ deep. The contribution of skeletal muscle signal to the specta was calculated to be $<5 \%$. We also obtained ${ }^{31}$ P-NMR spectra from a preparation within $10 \mathrm{~min}$ after excision of the heart. Only signals for 2,3-diphosphoglycerate and ATP in a ratio of 25:1 (characteristic of blood) could be detected. No skeletal muscle creatine phosphate signal could be detected from the cardiectomized rats at a time when the ischemic skeletal muscle creatine phosphate and ATP contents are $>99 \%$ of their control values (data not shown).

Magnetization transfer was observed when each broadband pulse was preceded by a low-power, narrowband pulse at the resonance frequency of [ $\gamma$-P]ATP for 0 to $4.8 \mathrm{~s}$. Separate studies showed that the narrowband pulse directly attenuated the creatine phosphate magnetization by $<5 \%$ when the carrier frequency was placed $350 \mathrm{~Hz}$ downfield from the resonance for creatine phosphate.

Magnetization areas for the [ $\beta$-P]ATP and creatine phosphate resonances were measured with the Nicolet integration program. During anesthesia with $1 \%$ halothane, myocardial ATP was set to $25 \mu \mathrm{mol} / \mathrm{g}$ dry weight (20) after subtracting the ATP estimated in the red cells that contributed to the $[\beta$-P]ATP resonance area. The myocardial ATP content during $2 \%$ halothane and norepinephrine infusion was normalized to the value obtained during $1 \%$ halothane after subtracting the estimate for red cell ATP. The ATP content of red cells was determined from the ratio of 2,3-diphosphoglycerate to ATP measured in blood drawn from the left ventricle at the end of the study. Under the NMR conditions for this study, the ratio of 2,3-diphosphoglycerate to ATP in red cells was 22.7 $\pm 3.4(n=6)$

Experimental protocol. Simultaneous hemodynamic and NMR measurements were made in animals under three experimental conditions: $2 \%$ halothane, $1 \%$ halothane, and $1 \%$ halothane plus norepinephrine infusion at $10 \mathrm{nmol} / \mathrm{min}$. The five animals were subjected to each condition in a random manner (2\%-1\%-N, N-1\%-2\%, $1 \%-\mathrm{N}-2 \%, 1 \%-2 \%-\mathrm{N}$, $\mathrm{N}-2 \%-1 \%$, where $2 \%=2 \%$ halothane, $1 \%=1 \%$ halothane, and $\mathrm{N}=$ norepinephrine). At the beginning of each experimental period, hemodynamic and myocardial contents of ATP and creatine phosphate were monitored until a steady state was achieved (typically within $14 \mathrm{~min}$, the time required for two unsaturated NMR spectra to be acquired for measurements of ATP and creatine phosphate to confirm metabolic steady state before each 50-min magnetization transfer experiment). Hemodynamic measurements were recorded continuously to insure physiologic steady state.

Blood gas measurements. In parallel experiments, blood gas measurements were made in four open-chest animals ventilated with room air and $1 \%$ halothane for $90 \mathrm{~min}$. Blood was withdrawn directly from left ventricular puncture and stored in heparinized glass syringes for 20 min until analysis (Corning $\mathrm{pH} /$ blood gas analyzer): $\mathrm{pH}=7.38 \pm 0.11$, $\mathrm{PO}_{2}=96 \pm 14 \mathrm{mmHg}, \mathrm{PCO}_{2}=37 \pm 9 \mathrm{mmHg}$, and hemoglobin $\mathrm{O}_{2}$ saturation $=97 \pm 1 \%$.

Electrocardiograms. Six-lead electrocardiograms were recorded from the limb attachments in four other open-chest animals outside the NMR spectrometer under each experimental condition. Pin electrodes $(0.5 \mathrm{~mm}$ copper wire) were placed subcutaneously and connected to a cable shielded with aluminum foil to eliminate $60-\mathrm{Hz}$ interference. The electrocardiograms were recorded with a Hewlett-Packard bioelectric $8811 \mathrm{~A}$ amplifier.

Epicardial pacing. To compare the hemodynamic effects of norepinephrine infusion to those of ventricular pacing, four open-chest animals had epicardial pacing leads (insulated $0.5 \mathrm{~mm}$ copper wire) attached atraumatically to the posterior left ventricular epicardial surface with cyanoacrylate (Krazy glue). The leads were attached to a S44 stimulator (Grass Instrument Co., Quincy, MA). The pacing threshold was $<0.5$ $\mathrm{mV}$ for each animal. The animals were paced at $360,420,480,540$, and 
600 beats per minute (bpm) for $10 \mathrm{~min}$ at each rate. Central aortic pressure was recorded continuously during the pacing.

Creatine content. After each animal had been subjected to the three experimental conditions and a lethal dose of halothane administered, $0.5 \mathrm{~g}$ of left ventricular tissue was removed immediately, blotted dry, and frozen at $-70^{\circ} \mathrm{C} .5$ to $10 \mathrm{mg}$ of the left ventricular tissue were later weighed and homogenized in $0.1 \mathrm{M} \mathrm{K}_{2} \mathrm{HPO}_{4}, \mathrm{pH} 7.4$, with $1 \mathrm{mM}$ EGTA $1 \mathrm{mM} \beta$-mercaptoethanol at $4^{\circ} \mathrm{C}$ for a final tissue concentration $5 \mathrm{mg} /$ $\mathrm{ml}$. Total creatine content was measured in these homogenates by using the method of Kammermeier (21).

Statistical analysis. The T1 for creatine phosphate and the pseudofirst order rate constant for the creatine kinase reaction were obtained by identifying the parameters for the single-exponential function between magnetization and saturation time with variance-weighted nonlinear regression analysis $(4,22)$. Differences for the rate-pressure products, ratios of creatine phosphate to ATP, rate constants, T1 values, and chemical flux values among the three experimental conditions were determined by using the multiple range test of Neumann-Keuls if a significant effect was proved by one-way analysis of variance (23). All calculations and regression analysis were performed with the research and statistics management package (Bolt, Beranek and Newman; VAX 11/ 780 Computer, Digital Equipment Corporation). All data are presented as mean \pm standard deviation.
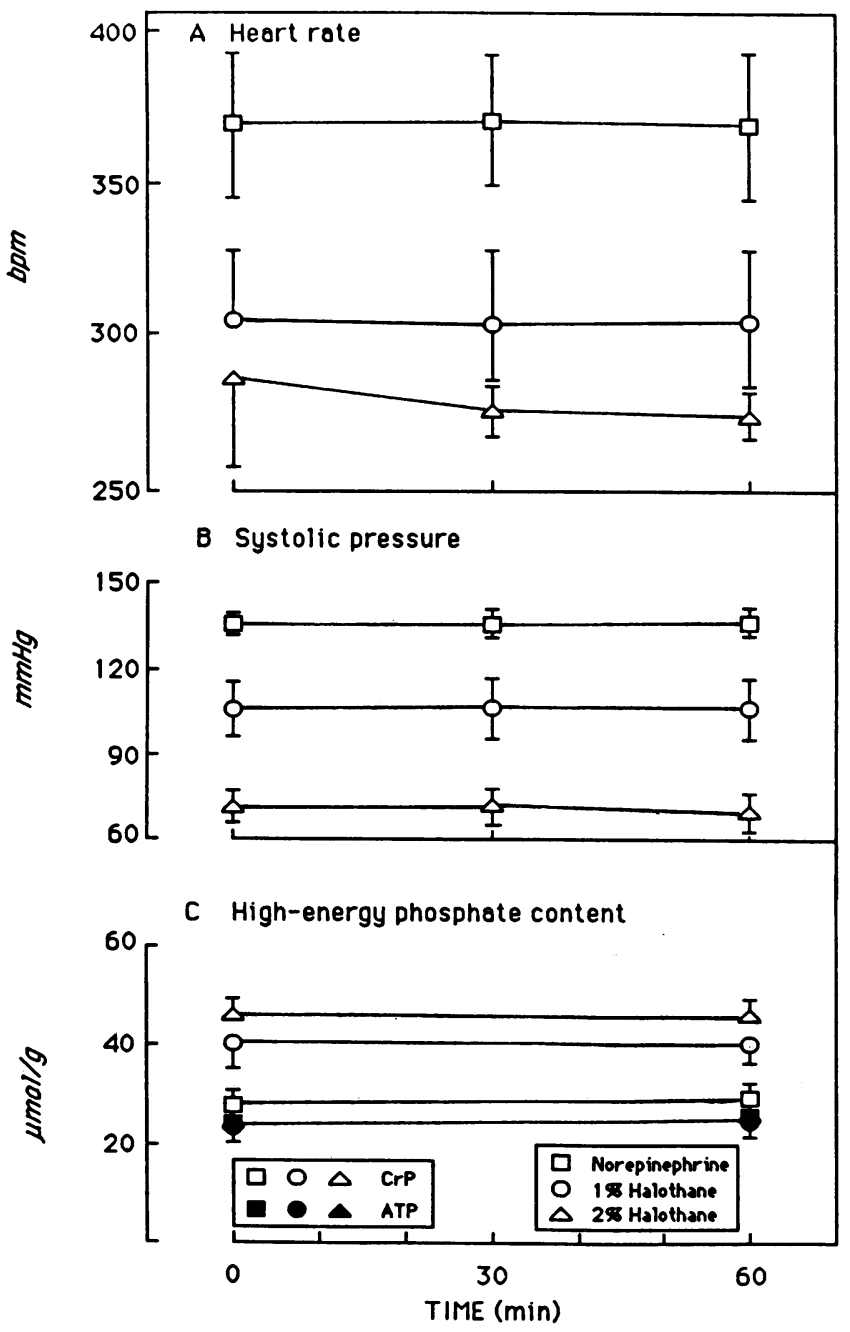

Figure 2. Hemodynamic and metabolic stability. Heart rate (beats per minute) and blood pressure were recorded continuously as NMR measurements of myocardial creatine phosphate and ATP were made during $2 \%$ halothane anesthesia $(n=4), 1 \%$ halothane $(n=5)$, or $1 \%$ halothane plus norepinephrine infusion $(n=4)$.

\section{Results}

Preparation stability. Five rats were intubated, instrumented, and inserted into the bore of the Nicolet NT360 spectrometer for simultaneous hemodynamic and NMR measurements under conditions of $2 \%$ halothane anesthesia or $1 \%$ halothane anesthesia with or without norepinephrine infusion. Norepinephrine produced no evidence of arrhythmia at an infusion rate of 10 $\mathrm{nmol} / \mathrm{min}$. In one animal, norepinephrine infusion at a rate of $100 \mathrm{nmol} / \mathrm{min}$ produced severe hypertension and an irregularly irregular rhythm consistent with atrial fibrillation. In another animal, the higher halothane dose produced eventual cardiac collapse. Accordingly, data from these two intervention periods were excluded from analysis.

All magnetization transfer measurements were made during a 60-min period of hemodynamic and metabolic steady state. We observed no significant change in heart rate, blood pressure, or myocardial ATP and creatine phosphate content during each 60-min observation period (Fig. 2). Furthermore, the hemodynamic and metabolic changes induced by norepinephrine infusion were completely reversible. In three animals, norepinephrine was infused during the first or second study period (see Methods). In these three animals myocardial creatine phosphate was $27.1 \pm 5.1 \mu \mathrm{mol} / \mathrm{g}$ dry weight and the systolic blood pressure $135 \pm 3 \mathrm{mmHg}$ during norepinephrine infusion. After the norepinephrine was discontinued, the creatine phosphate content increased to $41.6 \pm 4.3 \mu \mathrm{mol} / \mathrm{g}$ dry weight, which is indistinguishable from the control value of $40.7 \pm 0.4 \mu \mathrm{mol} / \mathrm{g}$ dry weight, as systolic blood pressure returned to the baseline value of $105 \pm 13 \mathrm{mmHg}$.

Inotropic stimulation. Varying the dose of halothane and infusing norepinephrine produced a wide range in cardiac performance. At a dose of $2 \%$ halothane, the mean heart rate and systolic blood pressure were $276 \pm 20 \mathrm{bpm}$ and $71 \pm 8 \mathrm{mmHg}$. At $1 \%$ halothane, the values for average heart rate and blood pressure rose to $308 \pm 20 \mathrm{bpm}$ and $105 \pm 13 \mathrm{mmHg}$. Norepinephrine infusion further increased the values for heart rate and blood pressure to $358 \pm 19 \mathrm{bpm}$ and $136 \pm 3 \mathrm{mmHg}$ (Table I). Electrocardiograms showed no ST segment shift or $\mathrm{T}$ wave changes to

Table I. Kinetic and Hemodynamic Results

\begin{tabular}{lccc}
\hline & \multicolumn{2}{l}{ Condition } \\
\cline { 2 - 4 } & $2 \%$ Halothane & $1 \%$ Halothane & Norepinephrine \\
\hline Rate-pressure product & $19.5 \pm 1.6 * 32.0 \pm 3.5 * 48.5 \pm 2.0$ \\
Flux $(\mu$ mol $/ g$ dry per $s)$ & $15.4 \pm 4.6$ & $20.5 \pm 2.0 * 30.1 \pm 7.9$ \\
Rate Constant $\left(k, s^{-1}\right)$ & $0.35 \pm 0.11$ & $0.50 \pm 0.10 * 1.17 \pm 0.16$ \\
T1 (creatine phosphate) & $2.4 \pm 0.2$ & $2.2 \pm 0.2$ & $2.6 \pm 0.3$ \\
Creatine phosphate/ & & & \\
$\quad$ ATP & $1.9 \pm 0.1$ & $1.6 \pm 0.1 *$ & $1.0 \pm 0.1$ \\
$n$ & 4 & 5 & 4 \\
\hline
\end{tabular}

The rate-pressure products $(1,000 \times \mathrm{mmHg} / \mathrm{min})$, flux measurements $(\mu \mathrm{mol} / \mathrm{g}$ dry weight per $\mathrm{s})$ and the pseudo-first order rate constants $\left(\mathrm{s}^{-1}\right)$ for the creatine kinase reaction, the $\mathrm{T} 1$ values $(\mathrm{s})$ for creatine phosphate, and the ratio of creatine phosphate to ATP were determined under conditions of $2 \%$ halothane, $1 \%$ halothane, or $1 \%$ halothane plus norepinephrine at $10 \mathrm{nmol} / \mathrm{min}$. All data are presented as mean \pm SD.

* Difference $(P<0.05)$ between adjacent group means if analysis of variance showed a significant difference. 
suggest subendocardial ischemia during halothane-induced hypotension or norepinephrine infusion (Fig. 3).

Epicardial pacing. Ventricular pacing consistently reduced systolic blood pressure (Fig. 4). Reduced systolic pressure was offset by the pacing rate so that the rate-pressure products increased from $30.7 \pm 4.3 \times 1,000 \mathrm{mmHg} / \mathrm{min}$ at the animals' intrinsic cardiac rhythm to a maximum of $35.6 \pm 5.8 \times 1,000$ $\mathrm{mmHg} / \mathrm{min}$ during pacing at a rate of $480 \mathrm{bpm}$. At high pacing rates, the hemodynamic recordings showed a preserved dicrotic notch and no "ringing," suggesting that the damping and frequency response of the transducer system permitted accurate blood pressure measurements. ${ }^{31} \mathrm{P}-\mathrm{NMR}$ measurements made at each pacing rate showed no change in myocardial creatine phosphate or ATP (data not shown). Atrial pacing was not attempted.

Simultaneous hemodynamic and magnetization transfer measurements. Since ventricular pacing produced only small changes in the rate-pressure product in the rat, we used norepinephrine infusion to increase cardiac performance for the study of myocardial energetics.

Fig. 5 shows an example of the simultaneous hemodynamic and NMR records for one animal studied under the three different levels of cardiac performance set by varying halothane dose and norepinephrine infusion. The rate-pressure product in this animal was $49.5 \times 1,000 \mathrm{mmHg} / \mathrm{min}$ under conditions of
$1 \%$ halothane plus norepinephrine, $29.4 \times 1,000 \mathrm{mmHg} / \mathrm{min}$ under $1 \%$ halothane alone, and $18.9 \times 1,000 \mathrm{mmHg} / \mathrm{min}$ under $2 \%$ halothane. The ${ }^{31} \mathrm{P}-\mathrm{NMR}$ spectra show the steady state levels of red cell 2,3-diphosphoglycerate, myocardial creatine phosphate, and ATP predominantly from heart. The resonance from inorganic phosphate could not be discriminated from the 2,3diphosphoglycerate lines.

At each level of cardiac performance, selective saturation at the $[\gamma-\mathrm{P}] \mathrm{ATP}$ resonance for 0.3 to $4.8 \mathrm{~s}$ provided direct evidence for chemical exchange via the creatine kinase reaction. As saturation time at [ $\gamma$-P]ATP increased, the magnetically invisible terminal phosphate of ATP exchanged with the phosphate of creatine phosphate. The exchange reached asymptote at $\sim 5 \mathrm{~s}$. Different rates of exchange, observed as differences in the decay in creatine phosphate magnetization with respect to saturation time, were found for the three different rate-pressure products. The decay of creatine phosphate magnetization was greatest during norepinephrine infusion and least when $2 \%$ halothane was used. This qualitative analysis suggests that chemical exchange via the creatine kinase reaction was greatest during norepinephrine infusion and least during $2 \%$ halothane anesthesia.

The NMR measurements yielded information about the steady state levels of myocardial ATP and creatine phosphate and red cell ATP and 2,3-diphosphoglycerate. Myocardial ATP ranged from $24.3 \pm 1.1$ to $25.6 \pm 1.1 \mu \mathrm{mol} / \mathrm{g}$ dry weight and
A Norepinephrine

B 18 Halothane

C 23 $\left.\begin{array}{r}\text { Holothane } \\ \mathrm{mmHg}^{100} \\ 0\end{array}\right]$
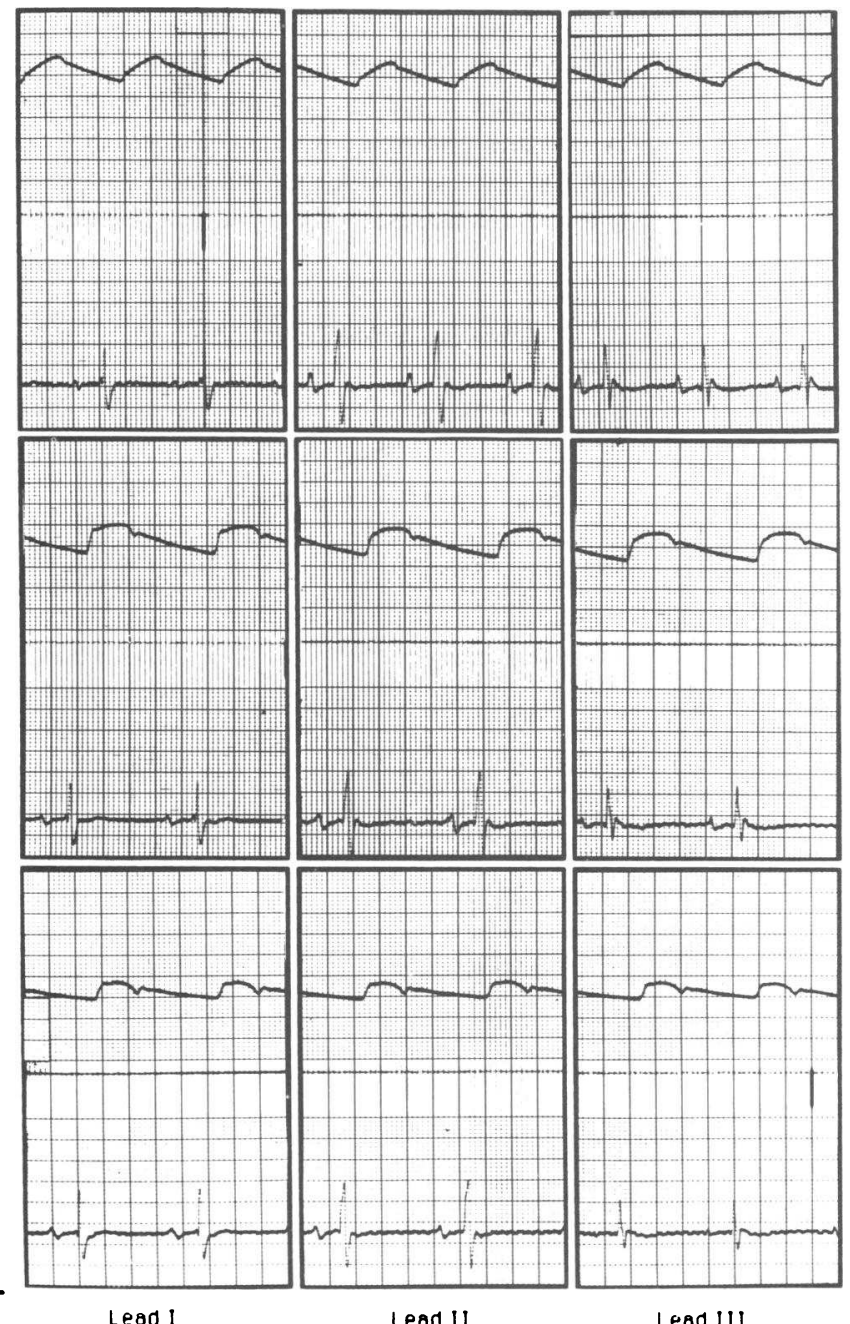

Figure 3. Electrocardiogram. Leads I, II, and III are taken from the six-lead electrocardiograms during $2 \%$ halothane or $1 \%$ halothane with or without norepinephrine. 


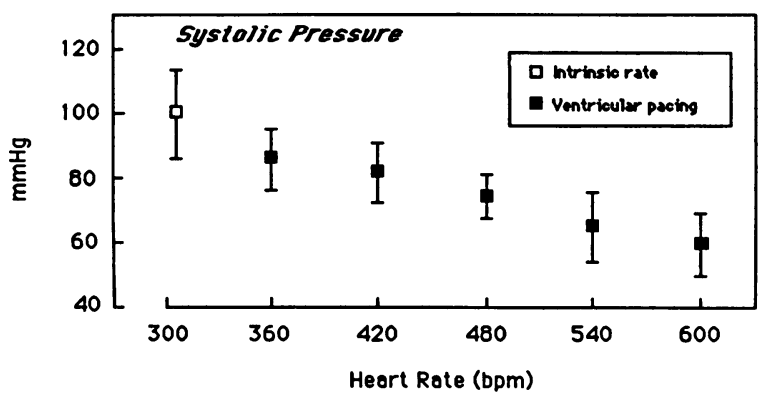

Figure 4. Pacing hemodynamics. Epicardial ventricular pacing at various rates for 10 min produced mild hypotension in four animals.

showed no dependence on cardiac performance. Myocardial creatine phosphate varied inversely with cardiac performance, ranging from a mean value of $26.0 \pm 6.5 \mu \mathrm{mol} / \mathrm{g}$ dry weight during norepinephrine infusion to $45.6 \pm 6.0 \mu \mathrm{mol} / \mathrm{g}$ dry weight under conditions of $2 \%$ halothane anesthesia. During anesthesia with $1 \%$ halothane, the myocardial creatine phosphate was $40.9 \pm 0.4$

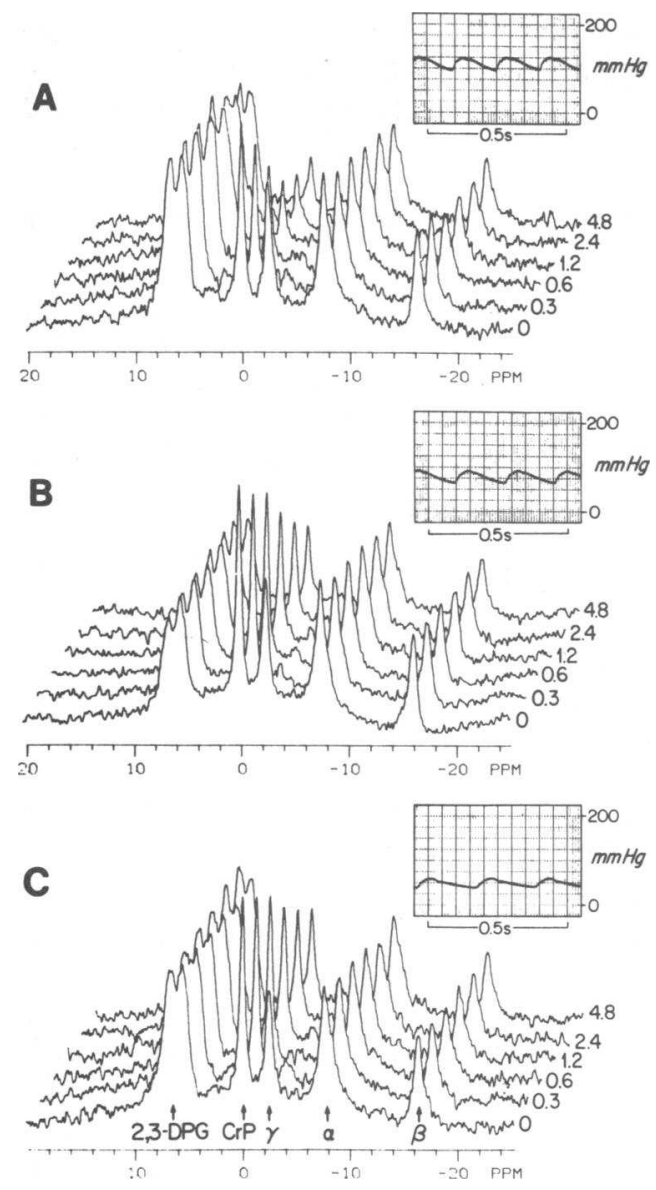

Figure 5. Hemodynamic and NMR records. Simultaneous central aortic pressure recording and ${ }^{31} \mathrm{P}-\mathrm{NMR}$ cardiac measurements were made sequentially in a rat during $1 \%$ halothane anesthesia with norepinephrine infusion at $10 \mathrm{nmol} / \mathrm{min}(A)$, halothane anesthesia without norepinephrine $(B), 2 \%$ halothane anesthesia alone $(C)$. Each ${ }^{31} \mathrm{P}-\mathrm{NMR}$ spectrum resulted from 32 scans with a 12.5-s interpulse delay after selective saturation at the [ $\gamma$-P]ATP resonance frequency for 0 to 4.8 s. 2,3-DPG, red cell 2,3-diphosphoglycerate; $\mathrm{CrP}$, myocardial creatine phosphate; $\gamma, \alpha$, and $\beta$, respective phosphorus atoms of ATP. $\mu \mathrm{mol} / \mathrm{g}$ dry weight and the ATP content was $25 \mu \mathrm{mol} / \mathrm{g}$ dry weight. The ratio of myocardial creatine phosphate to ATP was inversely related to cardiac performance (Table I). A small increase in NMR-visible 2,3-diphosphoglycerate was noted during norepinephrine infusion in three of four experiments, but this was not statistically significant. Increasing the halothane concentration produced no consistent change in the signal for red cell 2,3-diphosphoglycerate. The mean value for red cell ATP content was $3.2 \pm 0.7 \mu \mathrm{mol} / \mathrm{g}$ cardiac dry weight $(n=13)$.

Magnetization transfer experiments performed at the various levels of cardiac performance revealed that both the rate constants and the flux values for the creatine kinase reaction in the direction of ATP synthesis increased with cardiac performance (Table I). As cardiac performance increased over a 2.5fold range, we observed a 3.3-fold increase in the rate constant for the creatine kinase reaction and a 2.0 -fold increase in the flux through the forward direction of the reaction. The $\mathrm{T} 1$ values for creatine phosphate showed no dependence on cardiac performance (Table I).

Physiological chemistry of creatine kinase. By varying the dose of halothane and using norepinephrine infusion we obtained a 2.5-fold change in the rate-pressure product. Associated with this increase in rate-pressure product was a fall in the myocardial creatine phosphate content. Myocardial ATP did not change over the wide range in cardiac performance (Fig. $6 \mathrm{~A}$ ). The relationship between the rate constant for the creatine kinase reaction in the direction of ATP synthesis versus rate-pressure product defined a function with positive slope (Fig. $6 \mathrm{~B}$ ), showing that the rate constant is directly related to the level of cardiac performance in the intact animal. Multiplying the rate constant by creatine phosphate content yielded the value for chemical flux for the creatine kinase reaction in the direction of ATP synthesis. These results show that flux through the creatine kinase

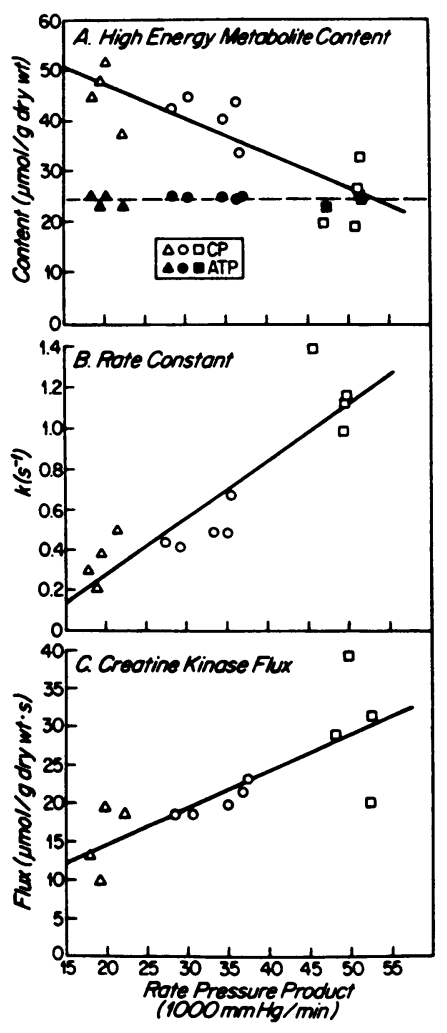

Figure 6. Physiological chemistry of creatine kinase. Myocardial ATP and creatine phosphate content $(A)$, the rate constant $(B)$, and the flux value $(C)$ for the forward direction of the creatine kinase reaction are related to the simultaneously measured rate-pressure product for five animals under $1 \%$ halothane anesthesia plus $10 \mathrm{nmol}$ norepinephrine/min ( $\square$ ), $1 \%$ halothane anesthesia without norepinephrine (0), or $2 \%$ halothane anesthesia alone $(\Delta)$. The regressions are defined by $(A)$ creatine phosphate (CP) $=-0.67 \mathrm{x}+60\left(r^{2}=0.69, P\right.$ $<0.001) ;$ ATP $=0.05 \mathrm{x}+24$ $\left(r^{2}=0.34, P=0.04\right) ;(B) k$ $=0.023 \mathrm{x}-0.28\left(r^{2}=0.82, P\right.$ $<0.001)$; and $(C)$ flux $=0.52 \mathrm{x}$ $+4.6\left(r^{2}=0.66 ; P<0.001\right)$. $\mathrm{CrP}$, creatine phosphate and $k$, rate constant. 
reaction increased with rate-pressure product in the intact animal (Fig. $6 C$ ).

Using the equilibrium constant of 166 for the creatine kinase reaction at physiologic $\mathrm{pH}(24)$ and the value of $3.23 \mathrm{~g}$ cell water/g dry weight for the blood-perfused rat heart (25), we converted myocardial content (expressed in $\mu \mathrm{mol} / \mathrm{g}$ dry weight) to cellular concentration (mM) and estimated values for the concentration of cytosolic ADP. We calculated [ADP] values of 17,32 , and $87 \mu \mathrm{M}$ for hearts under conditions of $2 \%$ halothane, $1 \%$ halothane, and $1 \%$ halothane plus norepinephrine, respectively (Table II). The 3.3-fold increase in the pseudo-first order unidirectional rate constant for the reaction is thus matched by a fivefold increase in the estimate for [ADP]. Based on values for free cytosolic ADP, we estimated values for the second-order rate constant and found no difference among the three conditions (Table II).

\section{Discussion}

Hemodynamic studies in the open-chest rat showed that cardiac performance, as estimated from the rate-pressure product, could be studied over a threefold range by using various halothane concentrations and a low dose of norepinephrine. NMR studies showed that the content of creatine phosphate varied inversely but reversibly with cardiac performance, whereas ATP content did not change. Magnetization studies suggested that the rate of ATP synthesis from creatine phosphate via the creatine kinase reaction increased with cardiac work. Thus, we observed that cardiac performance was matched to the level of high-energy phosphate turnover.

We studied myocardial energetics over a broad range of cardiac performance and energy utilization in the living animal. We used the rate-pressure product from central aortic recordings to provide an index of cardiac performance. Measuring oxygen consumption of the rat heart would have provided a better index of myocardial energy utilization than using the rate-pressure product, but this could not be measured at the various levels of cardiac performance in the living animal without cannulation of the coronary sinus.

Recognizing the need to study myocardial energetics under conditions of cardiac performance that are physiologically rel-

Table II. Terms for the Rate Equation

for the Creatine Kinase Reaction

\begin{tabular}{lcccc}
\hline & \multicolumn{2}{l}{ Condition } & & \\
\cline { 2 - 4 } & $2 \%$ Halothane & $1 \%$ Halothane & Norepinephrine & ANOVA \\
\hline Flux $(m M / s)$ & $4.8 \pm 1.4$ & $6.3 \pm 0.6 * 9.3 \pm 2.4$ & $*$ \\
$k^{\prime}\left(m M^{-1} \cdot s^{-1}\right)$ & $20 \pm 10$ & $16 \pm 12$ & $14 \pm 5$ & NS \\
{$[\mathrm{ADP}](\mu M)$} & $17 \pm 7$ & $31 \pm 21 * 87 \pm 28$ & $*$ \\
{$[\mathrm{CrP}](\mathrm{mM})$} & $14.7 \pm 0.8$ & $12.2 \pm 1.1 * 7.6 \pm 0.8$ & $*$ \\
\hline
\end{tabular}

Flux through the creatine kinase reaction, as determined by NMR methods, was converted to concentration units $(\mathrm{mM} / \mathrm{s})$ by using 3.23 $\mathrm{g}$ cell water/g dry weight (25) and compared to the individual components of the rate equation: $k^{\prime} \cdot[\mathrm{ADP}] \cdot[\mathrm{CrP}]$, where $k^{\prime}$ is second order rate constant $\left(\mathrm{mM}^{-1} \cdot \mathrm{s}^{-1}\right)$ estimated from the pseudo-first order rate constant, $k$, and from values for [ADP] $(\mu \mathrm{M})$. NS refers to no difference among the three groups by analysis of variance (ANOVA).

*Difference $(P<0.05)$ between adjacent group means if analysis of variance showed a significant difference. evant, we compared the hemodynamic effects of ventricular pacing to those of norepinephrine infusion and halothane anesthesia. We observed that a low dose of norepinephrine increased the heart rate and blood pressure to values reported for the unanesthetized rat (26), but pacing produced hypotension. The decrease in blood pressure with pacing at rapid pacing rates has been observed for all species studied and can be attributed to incomplete ventricular relaxation and inadequate ventricular filling (27). Decreased systolic pressure appears in the intact dog at heart rates $>200$ (27-29). Interestingly, one compensatory mechanism that tends to maintain systolic pressure in the dog is the "treppe" effect (the rate-related increase in contractility), which does not exist in the rat heart $(30,31)$. Thus, norepinephrine, whose concentration increases in rat plasma during stress (26), produces a more physiologically relevant range of cardiac performance than pacing by augmenting both the blood pressure and heart rate.

In addition to its more potent hemodynamic effects, norepinephrine infusion stimulates oxygen consumption to a greater degree than pacing even at identical values for the rate-pressure product $(1,32)$. For any level of peak developed tension in the isovolumetrically contracting dog heart, Graham et al. (1) found that norepinephrine infusion increased oxygen consumption by $50 \%$. Saito et al. (5) observed that the increase in myocardial oxygen consumption was six times greater for every $1 \mathrm{mmHg}$ rise in aortic pressure than for every $1 \mathrm{bpm}$ increase in heart rate in the dog. Boerth et al. (6) observed that the increase in myocardial oxygen consumption was five times greater for inotropic stimulation from norepinephrine than from atrial pacing. In each case, pacing produced only modest increases in oxygen consumption but pressure work stimulated oxygen consumption substantially. Thus, for any value for the rate-pressure product in the intact animal, oxygen consumption can vary widely depending on the presence of inotropic agents and the absolute level of blood pressure. Sonnenblick et al. (33) found that positive inotropic stimulation in the dog always increased myocardial oxygen consumption despite variable changes in the tensiontime index and the rate-pressure product. Although it increases myocardial energy utilization, norepinephrine infusion in the dog has been shown to augment coronary flow and produce smaller increases in cellular NADH levels than pacing (28). During norepinephrine infusion in this study, it is likely that myocardial oxygen consumption and energy utilization were greatly enhanced because of the combined pressor and inotropic effects that exceeded those of pacing.

We also observed small changes in cardiac performance by using two doses of halothane. Although all volatile anesthetics have cardiac depressant properties that are generally related to their potencies as general anesthetics (34), advantages of using halothane for this study include its lack of stimulation of the rat sympathetic nervous system even during hypotension (26) and its insignificant direct effect on the myocardial contents of highenergy phosphate compounds $(35,36)$. The results of this study also show that halothane does not depress myocardial high-energy phosphate content directly.

Over a wide range of cardiac performance, we observed no change in myocardial ATP content. In contrast, creatine phosphate content fell reversibly during inotropic stimulation with norepinephrine. The relationship between high-energy phosphate compounds and cardiac performance observed here is similar to that seen in the isolated perfused rat heart $(4,8,9)$ and in the dog heart in the living animal as wall stress is increased (7). It 
seems unlikely that myocardial ischemia produced the reversible changes in creatine phosphate content seen during the norepinephrine infusion in this study. The blood pressure and heart rates during norepinephrine infusion are equivalent to those in the unanesthetized rat (26), the animals would not be expected to have coronary disease, and no electrocardiographic changes of ischemia were observed. Although oxygen deprivation has been observed to depress myocardial creatine phosphate content, it decreases the flux values for the creatine kinase reaction (37) in contrast to the effect of norepinephrine.

Several similarities exist between the buffer-perfused, isolated heart and the blood-perfused heart in situ. In the present study, at the highest workload, the creatine phosphate/ATP ratio was identical for isolated and in situ hearts. Under low workload, the creatine phosphate/ATP ratio was $50 \%$ higher in the heart in the intact animal, probably reflecting differences in substrate metabolism between the glucose-supplied isolated heart versus the preferred nonglucose substrates in the living animal. Similar to the aqueous-perfused isolated heart (4), the heart in the living animal has $T 1$ values for creatine phosphate that do not vary with cardiac performance (Table I). Cardiac performance in the intact animal, coupled to myocardial oxygen consumption, and flux through the creatine kinase reaction in the direction of ATP synthesis increase concomitantly (Fig. $6 C$ ). Interestingly, the absolute value for flux is lower in the blood-perfused heart of the living animal than it is in the isolated heart. We measured flux values of $15.4 \pm 4.6 \mu \mathrm{mol} / \mathrm{g}$ dry weight per s at a rate-pressure product of $19.5 \times 1,000 \mathrm{mmHg} / \mathrm{min}$ in the living animal but calculate values for flux of $28.5 \pm 2.9 \mu \mathrm{mol} / \mathrm{g}$ dry weight per $\mathrm{s}$ in the isolated heart at a rate-pressure product of $15.2 \times 1,000$ $\mathrm{mmHg} / \mathrm{min}$ (4). The magnetization transfer measurements and numerical analysis were similar for the two sets of experiments. The different flux values between the aqueous-perfused heart and the blood-perfused heart may be due to differences in oxygen consumption, free cytosolic ADP concentration, or chemomechanical efficiency.

Over a range of cardiac performance that varied 2.5-fold, we observed a 3.3-fold increase in the pseudo-first order rate constant and a twofold increase in flux through the creatine kinase reaction. The decay in creatine phosphate magnetization with respect to saturation time yields an accurate value for the pseudo-first order rate constant for the creatine kinase reaction because creatine phosphate participates in no reaction other than creatine kinase. The 3.3-fold increase in the pseudo-first order rate constant was associated with a fivefold increase in estimated cytosolic [ADP]. This is an important observation because the magnetization transfer analysis used here simplifies the creatine kinase reaction to a first-order system. The forward direction of the creatine kinase reaction is a second-order process in both creatine phosphate and ADP. Flux can also be calculated from the rate equation: $k^{\prime}[\mathrm{ADP}] \cdot[\mathrm{CrP}]$ where the term $k^{\prime}[\mathrm{ADP}]$ is given by the pseudo-first order rate constant, $k$. Our results show that [ADP] is the term in the rate equation that changes most prominantly with cardiac performance. The 5.1 -fold increase in ADP cardiac performance offets the $45 \%$ decrease in creatine phosphate and produces a net increase in flux because $k^{\prime}$, the estimated second-order rate constant, does not change signifcantly (Table II). The results are also consistent with the notion that ADP regulates ATP synthesis both from oxidative phosphorylation and from creatine phosphate via the creatine kinase reaction.

The estimates for [ADP] help to resolve differences among the various studies on creatine kinase flux in the isolated heart. Matthews et al. (16) observed a 2.5-fold variation in estimated [ADP] in the isolated heart under various workloads and substrate supply. They concluded that [ADP] regulates flux through the creatine kinase reaction even though they observed no difference between flux and workload (or [ADP]). Maidan et al. (17), observing no significant relationship between flux and cardiac work, measured only a $10 \%$ change in the creatine phosphate/ATP ratio (in contrast to the change that we observed here). It seems likely that their measurements of flux were made over a range of cardiac performance and energy utilization that was associated with only small changes in [ADP]. In contrast, Kupriyanov et al. (9) observed an increase in creatine kinase flux measured over a wide range of cardiac performance that was associated with a $45 \%$ variation in the creatine phosphate/ ATP ratio. In the isolated heart, we observed a significant increase in flux through the reaction over a eightfold range in oxygen consumption and a $27 \%$ variation in the creatine phosphate/ ATP ratio (4). While no study has shown a 1:1 relationship between creatine kinase flux and cardiac performance, most investigators have observed an increase in flux in hearts when such measurements were made over a wide range of energy utilization as reflected by oxygen consumption, the ratio of creatine phosphate to ATP, or estimates for free ADP. Because of the inherent insensitivity of NMR methods, we have found that significant changes in flux over a range of cardiac performance can be observed only if the signal-to-noise for creatine phosphate is at least 25:1 and such measurements are made over at least a twofold range in myocardial oxygen consumption as estimated from the rate-pressure product during inotropic stimulation $(1,5,6$, 33). The average standard deviation for the measurement of flux in this study was $>25 \%$. Although we observed a $33 \%$ increase in flux between the $2 \%$ and $1 \%$ halothane conditions, this difference was not statistically significant.

In summary, we observed that myocardial creatine phosphate content varied inversely and reversibly with cardiac performance in the living rat during inotropic stimulation. Myocardial ATP content did not change with cardiac performance. Magnetization transfer experiments showed that estimates for ADP and the measured flux values for the creatine kinase reaction in the direction of ATP synthesis increase with cardiac performance in the living rat. Thus, flux through the creatine kinase reaction in the heart of the living animal may be determined in part by cytosolic ADP concentration and the rate of mitochondrial ATP synthesis. The results suggest the myocardial content of ATP bears no direct relationship with cardiac performance over a wide physiologic range. Instead, high-energy phosphate turnover is the energetic basis for cardiac performance in the living animal.

\section{Acknowledgments}

This work was supported by United States Public Health Service grant HL-26215 and a grant from the American Heart Association, Massachusetts Affiliate. Dr. Bittl was supported by Clinical Investigator Award HL-01517.

\section{References}

1. Graham, T. P., Jr., J. W. Covell, E. H. Sonnenblick, J. Ross, Jr., and E. Braunwald. 1972. Control of myocardial oxygen consumption: relative influence of contractile state and tension development. J. Clin. Invest. 47:275-339.

2. Feinberg, H., L. N. Katz, and E. Boyd. 1962. Determinants of 
coronary flow and myocardial oxygen consumption. Am. J. Physiol. 202:45-52.

3. Sarnoff, S. J., E. Braunwald, G. H. Welch, R. B. Case, W. N. Stainsby, and R. Macruz. 1958. Hemodynamic determinants of oxygen consumption of heart with special reference to the Tension-Time Index. Am. J. Physiol. 192:148-156.

4. Bittl, J. A., and J. S. Ingwall. 1985. Reaction reates of creatine kinase and ATP synthesis in the isolated rat heart. A 31P-NMR magnetization transfer study. J. Biol. Chem. 260:3512-3517.

5. Saito, D., K. Yasuhara, D. Nishiyama, S. Kusachi, and S. Haraoka. 1981. Comparative effects of heart rate and aortic blood pressure on MVO in the anesthetized open-chest dog. Jpn. Heart J. 22:833-837.

6. Boerth, R. C., K. E. Hammermeister, and J. R. Warbasse. 1978. Comparative influence of ouabain, norepinephrine and heart rate on myocardial oxygen consumption and inotropic state in dogs. Am. Heart J. 96:355-362.

7. Boerth, R. C., J. W. Covell, S. C. Seagren, and P. E. Pool. 1969. High-energy phosphate concentrations in the dog myocardium during stress. Am. J. Physiol. 216:1103-1106.

8. Matthews, P. M., S. R. Williams, A.-M. Seymour, A. Schwartz, G. Dube, D. G. Gadian, and G. K. Radda. 1982. A ${ }^{31}$ P-NMR study of some metabolic and functional effects of the inotropic agents epinephrine and ouabain and the ionophore R02-2985 (X537A) in the isolated, perfused rat heart. Biochem. Biophys. Res. Commun. 720:163-171.

9. Kupriyanov, V. V., A. Y. Steinsschneidner, E. K. Ruuge, V. I. Kapel'ko, M. Y. Zueva, V. L. Lakomkin, V. N. Smirnov, and V. A. Saks. 1984. Regulation of energy flux through the creatine kinase reaction in vitro and in perfused rat heart: 31P-NMR studies. Biochim. Biophys. Acta. 805:319-331.

10. Balaban, R. S., H. L. Kantor, L. A. Katz, and R. W. Briggs. 1986. Relation between work and phosphate metabolite in the in vivo paced mammalian heart. Science (Wash. DC). 232:1121-1123.

11. Jacobs, H., H. W. Heldt, and M. Klingenberg. 1964. High activity of creatine kinase in mitochondria from muscle and brain and evidence for separate mitochondrial isoenzyme of creatine kinase. Biochem. Biophys. Res. Commun. 16:516-521.

12. Jacobus, W. E., and A. L. Lehninger. 1973. Creatine kinase of rat heart mitochondria. Coupling of creatine phosphorylation to electron transport. J. Biol. Chem. 248:4803-4810.

13. Saks, V. A., N. V. Lipina, V. N. Smirnov, and E. I. Chazov. 1975. Studies of energy transport in heart cells. The functional coupling between mitochondrial creatine phosphokinase and ATP-ADP translocase: kinetic evidence. Arch. Biochem. Biophys. 173:34-41.

14. Turner, D. C., T. Wallimann, and H. M. Eppenburger. 1973. A protein that binds specifically to the M-line of skeletal muscle is identified as the muscle form of creatine kinase. Proc. Natl. Acad. Sci. USA. 70: 702-705.

15. Krause, S. M., and W. E. Jacobus. 1985. Maximal enhancement of the myofibrillar ATPase with MgATP generated by phosphocreatine via the myosin-bound creatine kinase. Circulation. 72(Suppl. III):III335. (Abstr.)

16. Matthews, P. M., J. L. Bland, D. G. Gadian, and G. K. Radda. 1982. A 31P-NMR saturation transfer study of the regulation of creatine kinase in the heart. Biochim. Biophys. Acta. 721:312-320.

17. Maidan, R. R., M. Petein, S. P. Michursky, A. H. L. From, and K. Ugurbil. 1985. Is creatine kinase flux regulated by workload? Circulation. 72:III-336. (Abstr.)

18. Miceli, M. V., J. A. Hoerter, and W. E. Jacobus. 1983. Evidence supporting the phosphocreatine-ATP energy transport shuttle in perfused rabbit hearts. A 31P-NMR saturation transfer study. Circulation. 68: III-65. (Abstr.)

19. Grossman, W. 1974. Cardiac catheterization and angiography. Lea and Febiger, Philadelphia. 103-115.

20. Ingwall, J. S. 1982. Phosphorus nuclear magnetic resonance spectroscopy of cardiac and skeletal muscles. Am. J. Physiol. 242:H729H744.

21. Kammermeier, H. 1973. Microassay of free and total creatine from tissue extracts by combination of chromatographic and fluorometric methods. Anal. Biochem. 56:341-345.

22. Forsen, S., and R. A. Hoffman. 1963. Study of moderately rapid chemical exchange reactions by means of nuclear magnetic double resonance. J. Chem. Phys. 39:2892-2901.

23. Zar, J. H. 1974. Biostatistical Analysis. Prentice-Hall, Englewood Cliffs, NJ. 130-181.

24. Veech, R. K., J. W. R. Lawson, N. W. Cornell, and H. A. Krebs. 1979. Cytosolic phosphorylation potential. J. Biol. Chem. 254:65386543.

25. Polimeni, P. I., and E. Page. 1980. Chloride distribution and exchange in rat ventricle. Am. J. Physiol. 238:C169-C176.

26. Hoffmann, W. E., C. Seals, D. J. Miletich, and R. F. Albrecht. 1985. Plasma and myocardial catecholamine levels in young and aged rats during halothane anesthesia. Neurobiol. Aging. 6:117-120.

27. Braunwald, E., R. L. Frye, and J. Ross, Jr. 1960. Studies on Starling's Law of the heart: Determinants of the relationship between left ventricular end-diastolic pressure and circumference. Circ. Res. 8: 1254-1263.

28. Acad, B. A., E. Guggenheimer, J. Sonn, and J. Kedem. 1983. Differential effects of various inotropic agents on the intracellular redox level in the in vivo dog heart. J. Cardiovasc. Pharmacol. 5:284-290.

29. Ogawa, S., L. S. Dreifus, P. N. Shenoy, S. K. Brockman, and B. V. Berkovits. 1978. Hemodynamic consequences of atrioventricular and ventriculoatrial pacing. $P A C E$. 1:8-15.

30. Langer, G. A., and T. L. Rich. 1986. Augmentation of sarcolemmal Ca by anionic amphophile: contractile response of three ventricular tissues. Am. J. Physiol. 250:H247-H254.

31. Brady, A. J., S. T. Tan, and N. V. Ricchiuti. 1979. Contractile force measured in unskinned isolated adult rat heart fibres. Nature (Lond.). 282:128-129.

32. Clancy, R. L., T. P. Graham, Jr., W. J. Powell, Jr., and J. P. Gilmore. 1967. Inotropic augmentation of myocardial oxygen consumption. Am. J. Physiol. 212:1055-1061.

33. Sonnenblick, E. H., J. Ross, Jr., J. W. Covell, G. A. Kaiser, and E. Braunwald. 1965. Velocity of contraction as determinant of myocardial oxygen consumption. Am. J. Physiol. 209:919-927.

34. Brown, B. R., and J. R. Crout. 1971. A comparative study of the effect of five general anesthetics on myocardial contractility. Anesthesiology. 34:236-245.

35. Dedrick, D. F., and P. D. Allen. 1983. NMR studies of myocardial high-energy phosphates and sodium as mediators of negative inotropic effects of volatile anesthetics. Anesthesiology. 59:A23. (Abstr.)

36. Murray, P., T. Blanck, M. Rogers, and W. E. Jacobus. 1983. Roles of myocardial high energy phosphates and intracellular $\mathrm{pH}$ of an inhalational anesthetic. Fed. Proc. 42:1258-1261. (Abstr.)

37. Bittl, J. A., J. S. Ingwall, and J. A. Balschi. 1986. Flux through the creatine kinase reaction in heart of living rat during hypoxia. Clin. Res. 34:283a. (Abstr.) 